\title{
Condições Higiênico-Sanitárias de Pequis Descascados Comercializados Sem Refrigeração
}

\author{
Laís Ramos Alves (I), Cristiane Silva Lopes Carneiro (I), Eder Júlio \\ de Jesus (I), Adélia Rodrigues Guimarães (I) \\ (I) FPU - Faculdade Pitágoras Campus Uberlândia-MG (Av. dos Vinhedos, 1200, Morada da \\ Colina, Uberlândia-MG.)
}

\section{Resumo}

INTRODUÇÃO O pequi (Caryocar brasiliense Camb.) é um fruto característico das regiões do cerrado brasileiro e constitui fonte de nutrientes para uso na alimentação humana, pois sua polpa é rica em vitamina A e pigmentos carotenóides. São comercializados nos grandes centros urbanos descascados e sem nenhuma refrigeração. Dessa forma, eles ficam expostos a possíveis contaminações microbiológicas ocasionadas pela manipulação inadequada dos vendedores, poeira das ruas, fuligem dos carros, falta de higiene do local de venda, o que podem ocasionar danos a saúde. Objetivou-se avaliar através de um check-list e análises microbiológicas a qualidade higiênico-sanitária de pequis descascados comercializados no mercado ambulante da cidade de Uberlândia-MG. MATERIAL E MÉTODOS O check-list utilizado é o que preconiza a RDC 216/04. As análises microbiológicas foram realizadas no SENAI/Uberlândia-MG de Salmonella sp., Coliformes a $35^{\circ} \mathrm{C}$ e a $45^{\circ} \mathrm{C}$ e Estafilococos coagulase positiva. Coletou-se quatro amostras de $1000 \mathrm{~g}$ (A, B, C e D), também em quatro locais distintos (L1, L2, L3 e L4); o checklist foi aplicado nesses locais. DISCUSSÃO DOS RESULTADOS A avaliação global de L1, L2, L3 e L4 para a aplicação das boas práticas de fabricação detectou 2,30\% de itens "conformes" (C), 96,38\% de itens considerados "não conformes" (NC) e de 1,31\% para o critério "não se aplica" (NA). De acordo com a ANVISA os estabelecimentos classificamse em Grupo 1, de 0 a 24\% de NC, Grupo 2, de 25 a $49 \%$ de NC e Grupo 3, 
de 50 a 100\% de NC. No presente estudo os locais L1, L2, L3 e L4 foram classificados no Grupo 3, insatisfatórios. As amostras A, B, C e D apresentaram ausência de Salmonella sp. e de Estafilococos coagulase positiva. Porém apresentaram coliformes a $35^{\circ} \mathrm{C}$ e a $45^{\circ} \mathrm{C}$, cuja variação foram de 9,2 (C) a >1.100 (A, B e D) e 43 (C) a >1.100 (A), respectivamente. Demonstrando assim, falta de higiene das amostras A, B, C e D comercializadas. CONCLUSÃO Os locais L1, L2, L3 e L4 não oferecem qualidade higiênica sanitária adequada para os pequis ali comercializados e podem trazer sérios riscos a saúde dos consumidores. Sugerimos maior atuação da Vigilância Sanitária Municipal para coibir tais vendas ambulantes na cidade de Uberlândia-MG.

Palavras-Chave: Caryocar brasiliense, Salmonella, higiene, refrigeração, estafilococos

Agência de Fomento: FPU 